Review Article

\title{
Preoperative Antihypertensive Medication in Relation to Postoperative Atrial Fibrillation in Patients Undergoing Cardiac Surgery: A Meta-Analysis
}

\author{
Ai-Guo Zhou, Xian-Xue Wang, Dao-Bo Pan, An-ji Chen, \\ Xiong-fei Zhang, and Hui-wei Deng \\ Department of Anesthesiology of the First People's Hospital of Changde City, Changde, Hunan, China \\ Correspondence should be addressed to Xian-Xue Wang; wxxxzyxy2013@163.com
}

Received 24 May 2016; Revised 8 October 2016; Accepted 2 November 2016; Published 13 February 2017

Academic Editor: Michael Gotzmann

Copyright ( $\odot 2017$ Ai-Guo Zhou et al. This is an open access article distributed under the Creative Commons Attribution License, which permits unrestricted use, distribution, and reproduction in any medium, provided the original work is properly cited.

Background. We undertake a systematic review and meta-analysis to evaluate the effect of preoperative hypertension and preoperative antihypertensive medication to postoperative atrial fibrillation (POAF) in patients undergoing cardiac surgery. Methods. We searched PubMed, Embase, and Cochrane Library (from inception to March 2016) for eligible studies. The outcomes were the effects of preoperative hypertension, preoperative calcium antagonists regimen, preoperative ACE inhibitors regimen, and preoperative beta blocking agents regimen with POAF. We calculated pooled risk ratios (OR) and 95\% CIs using randomor fixed-effects models. Results. Twenty-five trials involving 130087 patients were listed. Meta-analysis showed that the number of preoperative hypertension patients in POAF group was significantly higher $(P<0.05)$, while we found that there are no significant differences between two groups in Asia patients by subgroup analysis, which is in contrast to other outcomes. Compared with the Non-POAF group, the number of patients who used calcium antagonists and ACE inhibitors preoperatively in POAF group was significantly higher $(P<0.05)$. And we found that there were no significant differences between two groups of preoperative beta blocking agents used $(P=0.08)$. Conclusions. Preoperative hypertension and preoperative antihypertensive medication in patients undergoing cardiac operations seem to be associated with higher risk of POAF.

\section{Introduction}

Atrial fibrillation (AF) is a supraventricular tachyarrhythmia characterized by uncoordinated atrial activation with deterioration of mechanical function [1]. Postoperative atrial fibrillation (POAF) is the most common perioperative cardiac arrhythmia [2]. Although many studies have tried to assess risk factors for POAF, it remains incomplete and unclear. Moreover, patients with POAF have increased risk of stroke, other arrhythmias, cardiovascular mortality, and higher health-care costs compared with patients without POAF [3-5]. Constantly ascertaining the risk factors and prevention of POAF is of great importance for the physician.

Patient characteristics resulting in POAF are many. Some studies have confirmed that preoperative hypertension is a danger factor to POAF in patients with cardiac surgery [6-8], while a lot of studies suggestion that the number of preoperative hypertension patients has not significantly statistical differences between POAF group and Non-POAF group $[9,10]$. So we undertook a systematic review and metaanalysis to evaluate the effect of preoperative hypertension to POAF in patients with cardiac surgery.

\section{Methods}

This systematic review was performed according to the guidelines of the preferred reporting items for systematic reviews and meta-analyses (PRISMA) [6]. We prospectively registered our system review at PROSPERO (Registration number: CRD42016038101). The proposed study will utilize published data; as such there is no need for ethical approval.

2.1. Data Sources and Search Strategy. The PubMed, Embase, and Cochrane Library databases were searched from inception to February 2016 for relevant studies investigating the association between preoperation hypertension and POAF 
in cardiac surgical patients. The following search terms were used: Atrial fibrillation, "Fibrillation, atrial", Familial atrial fibrillation, Auricular fibrillation, "Fibrillation, auricular", Postoperative period, "Period, postoperative", Cardiac surgical procedures, "Procedure, cardiac surgical", "Surgical procedure, cardiac", "Surgical procedures, heart", Cardiac surgical procedure, Heart surgical procedures, "Procedure, heart surgical", "Surgical procedure, heart". A manual search of the reference sections of included trials, published metaanalyses, and relevant review articles was conducted to identify additional articles. If duplicated data were shown in several studies, only the most recent, largest, or most complete study was included.

Original studies included in our meta-analysis had to meet the following criteria: (1), an observation human study; (2) investigating the association between preoperative hypertension and POAF in cardiac surgical patients; (3) providing sufficient data to calculate them. Only English language studies were chosen.

2.2. Data Extraction and Assessment of Study Quality. Patient characteristics (authors, number of patients, year of publication, ASA rating, age, gender, type of surgery and anaesthesia, and endpoint) were recorded. If the data mentioned above were unavailable in the article, the corresponding authors were called upon for missing information. All of the data were independently extracted using a standard data collection form by both authors, and then the collected data were checked and entered into Review Manager analysis software (RevMan) Version 5.3. All discrepancies were checked, and a consensus was achieved by discussion. A record of reasons for excluding studies was kept.

The order from higher to lower in the quality of studies was the following: (1) prospective cohort study, (2) retrospective cohort study, and (3) case-control study. We evaluate the quality of the studies by Newcastle-Ottawa Scale (NOS) [11]: a maximum of nine points to each cohort study (four for quality of selection, two for comparability, and three for quality of outcome and adequacy of follow-up) and a score of nine points to every case-control study (four for quality of selection, two for comparability, and three for quality of exposure). The score of each study less than 6 was regarded as a low-quality study; otherwise, it was a high-quality study.

2.3. Statistical Analysis. The risk ratio (RR) with $95 \%$ CI was used as a common measure of the effect between the two groups. The meta-analysis was carried out using Review Manager, version 5.3 (The Cochrane Collaboration, Software Update, Oxford, UK). Statistical heterogeneity across studies was usually investigated using the $I^{2}$ statistic. When $I^{2}$ values of less than $50 \%$ were determined, heterogeneity could be accepted, and the fixed-effects model was expected to be adopted. Otherwise, the randomized-effects model was adopted, and we investigated the influence of a single study on the overall pooled estimate by omitting one study in each turn. A $P$ value of $<0.05$ was considered statistically significant.

To explore potential sources of heterogeneity among studies, we performed four sets of subgroup analysis: by

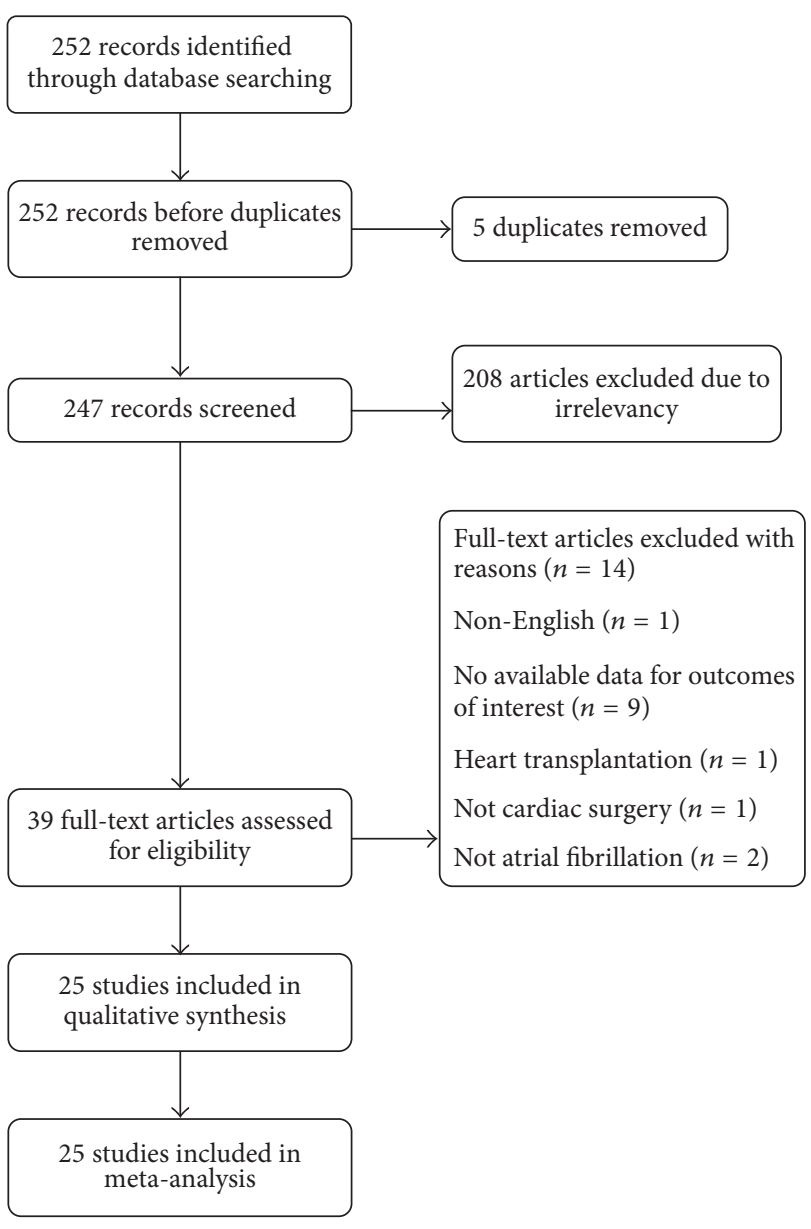

FIGURE 1: Flow diagram of search strategy and study selection.

study design (cohort versus case-control studies), by type of cardiac operation performed (coronary artery bypass grafting (CABG) only versus aortic valve replacement (AVR) only), by NOS scores (less than 6 versus with or higher 6), and by different region (Asia versus Europe versus America versus Oceania). We also performed a sensitivity analysis by excluding studies where the association between hypertension and POAF was opposite to the one from others.

\section{Results}

3.1. Identification of Eligible Studies. In total, 252 potentially relevant abstracts were identified. After duplicates were removed, 247 unique abstracts remained. After examining the abstracts, 39 publications seemed to meet the inclusion criteria. Of these, 14 were excluded for the following reasons: Non-English language [32], no available data on the outcome of interest in [33-41], heart transplantation [42], no cardiac surgery [43], and no atrial fibrillation [44, 45]. Finally, the remaining 25 studies [6-10, 12-31] to existing data met our selection criteria and were included in the systematic review. A flow diagram of the search strategy and study selection is illustrated in Figure 1. 


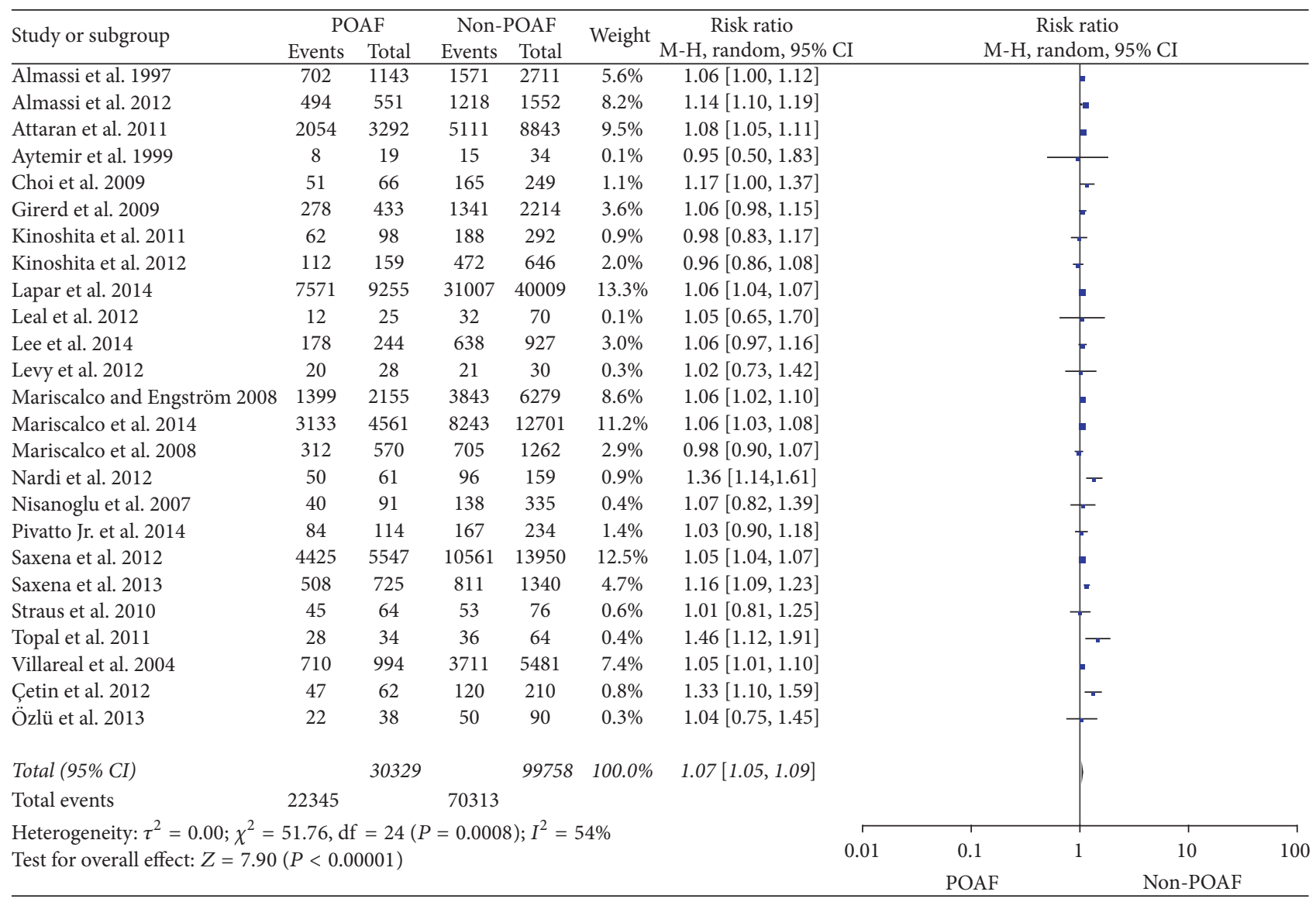

FIGURE 2: The effect of preoperative hypertension to POAF.

3.2. Study Characteristics. The characteristics of all included studies were presented in Table 1 . Most patients underwent CABG only; three studies reported Aortic valve replacements alone $[14,24,30]$. The type of cardiac operation in five studies contained CABG and valve operation [6, 13, 15, 22, 23]. These studies were published between 1997 and 2014. All studies clearly indicated the study population and defined the outcome. Sample size of included studies varied from 53 to 49264.

Eleven studies were cohorts $[8,10,13,23,24,26-31]$ and the rest were case-control studies $[6,7,9,12,14-22$, 25]. The quality of the included studies was assessed by NOS score. High NOS score of the studies included was 20 and the mean score was 6.12 (range from 2 to 8). Quality assessment of the 25 studies was shown in Table 1 . Three studies performed logistic regression analysis of preoperative drug administration for POAF in Table 2.

\subsection{Meta-Analysis of Primary Outcomes}

3.3.1. The Effect of Preoperative Hypertension to POAF. The aggregated results were studied in 25 trials [6-10, 12-31] and illustrated in Figure 2. Heterogeneity was noted among the studies $\left(I^{2}=54 \% ; P=0.0008\right)$, and a randomized-effects model was chosen. The results indicate that the number of preoperative hypertension patients in POAF group was significantly higher than Non-POAF group $(R R=1.07,95 \%$ CI: 1.05-1.09, $P<0.00001)$. After investigating the influence of a single study on the overall pooled estimate by omitting one study in each turn, we found that the $I^{2}$ is still higher than 50 except for one study [8]. When we omit the study of Almassi's [8], the $I^{2}$ drop to $38 \%$ and a fixed-effects model was selected, and the outcome between two groups has a significant difference $(\mathrm{RR}=1.06,95 \% \mathrm{CI}: 1.05-1.07, P<$ 0.00001) (Figure 3).

3.3.2. Subgroup Analysis between Preoperative Hypertension and $P O A F$. We performed subgroup analysis among studies to further demonstrate the relations of preoperative hypertension and POAF and explore potential sources of heterogeneity, while heterogeneity still existed (Table 3 ). Dividing the different regions that studies come from, statistically significant relations were observed for Europe $(\mathrm{RR}=1.08$; 95\% CI: $1.04-1.12 ; P<0.0001)$ and America (RR $=1.07 ; 95 \%$ CI: $1.04-1.11 ; P<0.00001)$, while there were no significant difference in Asia ( $\mathrm{RR}=1.03$; 95\% CI: 0.97-1.09; $P=0.32$ ) and Oceania regions $(\mathrm{RR}=1.10 ; 95 \% \mathrm{CI}: 1.00-1.21 ; P=$ 0.05). By observing the different study design, we found that the preoperative hypertension was significantly associated with POAF in cohort studies (RR $=1.11 ; 95 \% \mathrm{CI}$ : $1.05-1.17$; $P=0.0002)$ and case-control studies $(\mathrm{RR}=1.06 ; 95 \%$ CI: 1.05-1.07; $P<0.00001)$. Dividing the studies into the 
TABLE 1: Characteristics of the 25 studies included in the meta-analysis.

\begin{tabular}{|c|c|c|c|c|c|c|c|}
\hline Study & $\begin{array}{c}\text { Number of } \\
\text { patients } \\
\text { (AF/non-AF) } \\
\end{array}$ & Country & Study design & $\begin{array}{c}\text { Style of } \\
\text { operation }\end{array}$ & OR (95\% CI) & Definition of AF & $\begin{array}{l}\text { NOS } \\
\text { points }\end{array}$ \\
\hline Lee et al. 2014 & $244 / 927$ & Korea & Case-control & CABG & NA & $\begin{array}{c}\text { Postoperative atrial } \\
\text { fibrillation was defined as } \\
\text { newly developed AF } \\
\text { documented by } \\
\text { electrocardiography (ECG) } \\
\text { or continuous monitoring } \\
\text { during the first } 10 \text { days after } \\
\text { surgery }\end{array}$ & 8 \\
\hline $\begin{array}{l}\text { Mariscalco } \\
\text { and } \\
\text { Engström } \\
2008\end{array}$ & $2155 / 6279$ & Sweden & Case-control & $\begin{array}{l}\text { Cardiac } \\
\text { surgery }\end{array}$ & NA & $\begin{array}{l}\text { The AF definition included } \\
\text { arrhythmia successfully } \\
\text { treated as well as those } \\
\text { persistent at discharge. The } \\
\text { arrhythmia, as defined by } \\
\text { physician assessment, was } \\
\text { on the basis of a telemetry } \\
\text { strip or from a 12-lead } \\
\text { electrocardiogram } \\
\text { recording }\end{array}$ & 7 \\
\hline $\begin{array}{l}\text { Pivatto Jr. et } \\
\text { al. } 2014\end{array}$ & $114 / 234$ & Brazil & Case-control & AVR & NA & $\begin{array}{l}\text { AF consisted of any episode } \\
\text { of supraventricular } \\
\text { arrhythmia whose } \\
\text { electrocardiography tracing } \\
\text { showed "f" waves with } \\
\text { varying morphology and } \\
\text { amplitude as well as } \\
\text { irregular ventricular } \\
\text { rhythm }\end{array}$ & 4 \\
\hline $\begin{array}{l}\text { Attaran et al. } \\
2011\end{array}$ & $3292 / 8843$ & $\begin{array}{l}\text { United } \\
\text { Kingdom }\end{array}$ & Case-control & $\begin{array}{l}\text { Cardiac } \\
\text { surgery }\end{array}$ & NA & $\begin{array}{c}\text { AF, confirmed on } \\
\text { electrocardiogram (ECG) } \\
\text { for any length of time }\end{array}$ & 8 \\
\hline $\begin{array}{l}\text { Girerd et al. } \\
2009\end{array}$ & $433 / 2214$ & Canada & Case-control & CABG & $\begin{array}{c}\text { Hypertension: OR } \\
=0.89 \text { ( } 0.68 \text { to } 1.16) \\
\text { Preoperative drugs: } \\
\text { beta blockers: OR } \\
=1.03(0.77 \text { to } 1.39) \\
\text { ACEI and/or } \\
\text { ARBs: OR = } 1.26 \\
\text { (0.98 to } 1.61) \\
\text { Calcium } \\
\text { channel-blockers: } \\
\text { OR = } 1.18(0.92 \text { to } \\
1.52) \\
\end{array}$ & $\begin{array}{l}\text { AF was defined as any } \\
\text { sustained episode recorded } \\
\text { during the postoperative } \\
\text { hospital stay and requiring } \\
\text { medical and/or electrical } \\
\text { cardioversion }\end{array}$ & 6 \\
\hline $\begin{array}{l}\text { Kinoshita et } \\
\text { al. } 2012\end{array}$ & $159 / 646$ & Japan & Case-control & CABG & $\begin{array}{c}\text { Hypertension: OR } \\
=0.85 \text { ( } 0.58 \text { to } 1.18) \\
\text { Preoperative drugs: } \\
\text { beta blockers: OR } \\
=0.91(0.61 \text { to } 1.41) \\
\text { ACEI and/or } \\
\text { ARBs: OR }=0.93 \\
(0.60 \text { to } 1.44)\end{array}$ & $\begin{array}{l}\text { The endpoint was } \\
\text { new-onset AF after surgery, } \\
\text { which was diagnosed when } \\
\text { there was an irregular } \\
\text { cardiac rhythm without p } \\
\text { waves lasting more than } \\
60 \text { min that required } \\
\text { further administration of } \\
\text { antiarrhythmics, } \\
\text { cardioversion, or } \\
\text { anticoagulation } 8 \text { therapy }\end{array}$ & 6 \\
\hline
\end{tabular}


TABle 1: Continued.

\begin{tabular}{|c|c|c|c|c|c|c|c|}
\hline Study & $\begin{array}{c}\text { Number of } \\
\text { patients } \\
\text { (AF/non-AF) }\end{array}$ & Country & Study design & $\begin{array}{c}\text { Style of } \\
\text { operation }\end{array}$ & OR $(95 \%$ CI $)$ & Definition of AF & $\begin{array}{l}\text { NOS } \\
\text { points }\end{array}$ \\
\hline $\begin{array}{l}\text { Villareal et al. } \\
2004\end{array}$ & $994 / 5481$ & $\begin{array}{l}\text { United } \\
\text { States }\end{array}$ & Case-control & CABG & NA & $\begin{array}{l}\text { Postoperative AF was } \\
\text { defined by the } \\
\text { documentation of AF of } \\
\text { any duration at any time in } \\
\text { the postoperative period on } \\
\text { a physician assessment, on } \\
\text { the basis of a rhythm strip } \\
\text { or } 12 \text {-lead } \\
\text { electrocardiogram } \\
\text { recording }\end{array}$ & 8 \\
\hline
\end{tabular}

\begin{tabular}{|c|c|c|c|c|c|}
\hline $\begin{array}{l}\text { Topal and } \\
\text { Eren } 2011\end{array}$ & $34 / 64$ & Turkey & Case-control & CABG & NA \\
\hline $\begin{array}{l}\text { Kinoshita et } \\
\text { al. } 2011\end{array}$ & $98 / 292$ & Japan & Case-control & CABG & $\begin{array}{c}\text { Hypertension: OR } \\
=0.92(0.59 \text { to } 1.43) \\
\text { Preoperative drugs: } \\
\text { beta blockers: OR } \\
=0.79(0.44 \text { to } \\
1.28) \\
\text { ACEI and/or } \\
\text { ARBs: OR }=0.90 \\
(0.59 \text { to } 1.38)\end{array}$ \\
\hline
\end{tabular}

Saxena et al. 5547/13950 Australia Case-control CABG
2012

POAF was defined as evidence of new AF that required treatment by electrocardiography or continuous monitoring

The endpoint was new-onset $\mathrm{AF}$ after operation, which was diagnosed when there was an irregular cardiac rhythm without $\mathrm{p}$ waves lasting more than 60 minutes during the postoperative period

\begin{tabular}{lccccc}
\hline $\begin{array}{l}\text { Lapar et al. } \\
2014\end{array}$ & $9255 / 40009$ & $\begin{array}{l}\text { United } \\
\text { States }\end{array}$ & Case-control & $\begin{array}{l}\text { Cardiac } \\
\text { surgery }\end{array}$ & NA \\
\hline & & & & \\
Almassi et al. & $551 / 1552$ & $\begin{array}{l}\text { United } \\
\text { States }\end{array}$ & Cohort & CABG & $\begin{array}{l}\text { Hypertension: OR } \\
=1.76(1.23 \text { to } 2.50)\end{array}$
\end{tabular}

\section{AF was defined as any} abnormal atrially

\begin{tabular}{|c|c|c|c|c|c|c|c|}
\hline & & & & & & ninut & \\
\hline $\begin{array}{l}\text { Almassi et al. } \\
1997\end{array}$ & $1143 / 2712$ & $\begin{array}{l}\text { United } \\
\text { States }\end{array}$ & Cohort & $\begin{array}{l}\text { Cardiac } \\
\text { Surgery }\end{array}$ & NA & NA & 6 \\
\hline $\begin{array}{l}\text { Mariscalco et } \\
\text { al. } 2008\end{array}$ & $570 / 1262$ & Italy & Cohort & CABG & NA & NA & 7 \\
\hline
\end{tabular}
originated irregular rhythm $\quad 7$ lasting more than 30 minutes

POAF was defined as evidence of new AF that required treatment and was discovered by electrocardiography or continuous monitoring during the postoperative period.

Saxena et al. 2013

$725 / 1340$

Australia

Cohort

AVR

NA period.

We defined AF occurrence as any $\mathrm{AF}$ episode requiring any type of medical

Leal et al. $25 / 70$

Brazil Case-control

CABG

NA treatment and/or lasting for more than 20 min within the hospital stay period

Choi et al. 2009

$66 / 249$

Korea

Cohort

CABG

NA

NA 
TABle 1: Continued.

\begin{tabular}{|c|c|c|c|c|c|c|c|}
\hline Study & $\begin{array}{c}\text { Number of } \\
\text { patients } \\
\text { (AF/non-AF) }\end{array}$ & Country & Study design & $\begin{array}{c}\text { Style of } \\
\text { operation }\end{array}$ & OR (95\% CI) & Definition of AF & $\begin{array}{l}\text { NOS } \\
\text { points }\end{array}$ \\
\hline $\begin{array}{l}\text { Nardi et al. } \\
2012\end{array}$ & $61 / 159$ & Italy & Cohort & CABG & $\begin{array}{c}\text { Hypertension: OR } \\
=1.71(0.89 \text { to } 2.26) \\
\text { Preoperative drugs: } \\
\text { beta blockers: OR } \\
=0.91(0.33 \text { to } \\
20.46) \\
\text { ACEI and/or } \\
\text { ARBs: OR }=0.85 \\
\text { (0.33 to } 20.17)\end{array}$ & $\begin{array}{l}\text { POAF, defined as any } \\
\text { evidence of new AF by } \\
\text { electrocardiography or } \\
\text { continuous ECG } \\
\text { monitoring, lasting at least } \\
30 \text { seconds during the } \\
\text { postoperative period in our } \\
\text { hospital }\end{array}$ & 6 \\
\hline $\begin{array}{l}\text { Özlü et al. } \\
2013\end{array}$ & $38 / 90$ & Turkey & Cohort & CABG & NA & $\begin{array}{l}\text { Presence of POAF lasting } \\
\text { more than } 5 \text { min during } \\
\text { hospitalization was } \\
\text { detected by using } \\
\text { continuous telemetry or } \\
\text { 12-lead electrocardiography }\end{array}$ & 4 \\
\hline $\begin{array}{l}\text { Çetin et al. } \\
2012\end{array}$ & $62 / 210$ & Turkey & Cohort & CABG & $\begin{array}{c}\text { Hypertension: OR } \\
=1.638(0.728 \text { to } \\
3.687) \\
\text { Preoperative drugs: } \\
\text { calcium } \\
\text { channel-blockers: } \\
\text { OR }=1.929(0.627 \\
\text { to } 5.935) \\
\end{array}$ & $\begin{array}{l}\text { POAF was defined as any } \\
\text { episode of atrial fibrillation } \\
\text { within the hospital stay } \\
\text { after CABG surgery }\end{array}$ & 6 \\
\hline $\begin{array}{l}\text { Levy et al. } \\
2012\end{array}$ & $28 / 30$ & France & Cohort & AVR & NA & $\begin{array}{c}\text { POAF combined } \\
\text { paroxysmal and persistent } \\
\text { AF. Paroxysmal AF was } \\
\text { defined as self-terminating } \\
\text { AF, usually within } 48 \text { hours. } \\
\text { Persistent AF was defined } \\
\text { as an AF episode that lasted } \\
\text { longer than } 7 \text { days or } \\
\text { required termination by } \\
\text { cardioversion }\end{array}$ & 7 \\
\hline $\begin{array}{l}\text { Mariscalco et } \\
\text { al. } 2014\end{array}$ & $4561 / 12701$ & $\begin{array}{l}\text { United } \\
\text { Kingdom }\end{array}$ & Case-control & $\begin{array}{l}\text { Cardiac } \\
\text { surgery }\end{array}$ & NA & $\begin{array}{l}\text { POAF was documented on } \\
\text { the basis of a rhythm strip } \\
\text { or 12-lead ECG as } \\
\text { previously described }\end{array}$ & 7 \\
\hline $\begin{array}{l}\text { Aytemir et al. } \\
1999\end{array}$ & $19 / 34$ & Turkey & Cohort & CABG & NA & NA & 5 \\
\hline $\begin{array}{l}\text { Nisanoglu et } \\
\text { al. } 2007\end{array}$ & $91 / 335$ & Turkey & Case-control & CABG & $\begin{array}{l}\text { Hypertension: OR } \\
=1.12(0.70 \text { to } 1.79)\end{array}$ & $\begin{array}{l}\text { AF was diagnosed if 12-lead } \\
\text { ECG showed rapid } \\
\text { oscillations or fibrillatory p } \\
\text { waves that varied in size, } \\
\text { shape, and timing, } \\
\text { associated with irregular } \\
\text { QRS complexes. For this } \\
\text { study, postoperative }\end{array}$ & 7 \\
\hline $\begin{array}{l}\text { Straus et al. } \\
2010\end{array}$ & $64 / 76$ & Yugoslavia & Cohort & CABG & NA & NA & 2 \\
\hline
\end{tabular}

$\mathrm{AF}=$ atrial fibrillation; $\mathrm{CI}=$ confidence interval; $\mathrm{NOS}=$ Newcastle-Ottawa Scale; $\mathrm{OR}=$ odds ratio; $\mathrm{NA}=$ not available

high-quality and low-quality, statistically significant relations were observed for less than 6 ( RR $=1.13$; 95\% CI: $1.01-$ 1.26; $P=0.03)$ and higher or with $6(\mathrm{RR}=1.07 ; 95 \% \mathrm{CI}$ : $1.05-1.09 ; P<0.00001)$. The preoperative hypertension was also significantly associated with POAF in different type of cardiac operation performed, CABG alone (RR $=1.07 ; 95 \%$ CI: $1.05-1.09 ; P<0.00001)$, and AVR only (RR $=1.13 ; 95 \%$ CI: 1.07-1.20; $P<0.0001$ ) (Table 3). 
TABLE 2: Logistic regression analysis of preoperative medication for POAF.

\begin{tabular}{|c|c|c|c|c|}
\hline Study & OR & $95 \% \mathrm{CI}$ & $P$ level & $\begin{array}{c}\text { Model of logistic regression } \\
\text { analysis } \\
\end{array}$ \\
\hline \multicolumn{4}{|l|}{ Girerd et al 2009} & \multirow{3}{*}{$\begin{array}{l}\text { Multivariable logistic } \\
\text { regression analysis }\end{array}$} \\
\hline Calcium channel-blockers & 1.18 & $0.92-1.52$ & 0.18 & \\
\hline ACE-inhibitors & 1.26 & $0.98-1.61$ & 0.07 & \\
\hline \multicolumn{4}{|l|}{ Nardi et al. 2012} & \multirow{2}{*}{$\begin{array}{l}\text { Multivariable logistic } \\
\text { regression analysis }\end{array}$} \\
\hline ACE-inhibitors & 0.85 & $0.33-20.17$ & 0.74 & \\
\hline \multicolumn{4}{|l|}{ Çetin et al. 2012} & \multirow{2}{*}{$\begin{array}{l}\text { Binary logistic regression } \\
\text { analysis }\end{array}$} \\
\hline Calcium channel-blockers & 1.929 & $0.627-5.935$ & 0.252 & \\
\hline
\end{tabular}

TABLE 3: Subgroup analysis between preoperative hypertension and POAF.

\begin{tabular}{|c|c|c|c|c|c|}
\hline Variable & Number of studies & RR (95\% CI) & $I^{2}$ & Effects models & $P$ value \\
\hline \multicolumn{6}{|l|}{ Different region } \\
\hline Asia & 4 & $1.03(0.97-1.09)$ & 32 & Fixed effects models & 0.32 \\
\hline Europe & 12 & $1.08(1.04-1.12)$ & 53 & Random effects models & $<0.0001$ \\
\hline America & 7 & $1.07(1.04-1.11)$ & 61 & Random effects models & $<0.00001$ \\
\hline Oceania & 2 & $1.10(1.00-1.21)$ & 87 & Random effects models & 0.05 \\
\hline \multicolumn{6}{|l|}{ Study design } \\
\hline Case-control & 14 & $1.06(1.05-1.07)$ & 0 & Fixed effects models & $<0.00001$ \\
\hline Cohort & 11 & $1.11(1.05-1.17)$ & 61 & Random effects models & 0.0002 \\
\hline \multicolumn{6}{|c|}{ Study quality score } \\
\hline NOS $\geq 6$ & 20 & $1.07(1.05-1.09)$ & 57 & Random effects models & $<0.00001$ \\
\hline NOS $<6$ & 5 & $1.13(1.01-1.26)$ & 25 & Fixed effects models & 0.03 \\
\hline \multicolumn{6}{|l|}{ Style of operation } \\
\hline CABG & 17 & $1.07(1.05-1.09)$ & 53 & Random effects models & $<0.00001$ \\
\hline AVR & 3 & $1.13(1.07-1.20)$ & 23 & Fixed effects models & $<0.0001$ \\
\hline
\end{tabular}

3.3.3. Preoperative Calcium Antagonists Regimen with POAF. Seven studies $[6,12,13,16,23,26,29]$ with a total of 26921 patients reported preoperative calcium antagonists applied association with POAF. Heterogeneity among studies could be accepted $\left(I^{2}=41 \% ; P=0.12\right)$, and a fixed-effects model was selected. Compared with the Non-POAF group, the number of patients who used calcium antagonists in POAF group was significantly greater (RR: 1.12, 95\% CI: 1.08-1.17, $P<0.00001$ ) (Figure 4).

3.3.4. Preoperative ACE Inhibitors Regimen with POAF. Ten studies $[6,12,13,16,17,20,26,27,29,30]$ compared the preoperative ACE inhibitors used between two groups. There were no heterogeneity among the studies $\left(I^{2}=0 \% ; P=0.88\right)$, and a fixed-effects model was chosen. After integrating the data, people who applied ACE inhibitors before operation were significantly greater in POAF group when compared with Non-POAF group (RR: 1.04, 95\% CI: 1.01-1.08, $P=0.01$ ) (Figure 5).

3.3.5. Preoperative Beta Blocking Agents Regimen with POAF. Thirteen studies $[6,9,12,13,16,17,20,23,26-30]$ compared the preoperative beta blocking agents used in the POAF group and Non-POAF group. There was no heterogeneity among the studies $\left(I^{2}=0 \% ; P=0.96\right)$, and a fixedeffects model was chosen. After examining the studies by meta-analysis, we found that there were not significant difference between two groups of preoperative beta blocking agents used (RR: 0.98, 95\% CI: 0.96-1.00, $P=0.08$ ) (Figure 6).

\section{Discussion}

This is the first time meta-analysis to discuss the effect of preoperative hypertension to POAF. The pooled meta-analysis of 25 studies suggested that patients who have hypertension before operation were easier to develop AF postoperative. Preoperative ACE inhibitors and calcium antagonists regimen may be risk factors for POAF in patients undergoing cardiac surgery. In addition, patients with preoperative beta blocking agents were not linked with POAF.

People with hypertension are liable to suffer left atrial enlargement by the increased cardiac afterload, which was leading to atrial remodeling following the progression of disease [46]. Hypertension caused left ventricular hypertrophy and increases left ventricular stiffness, decreases coronary flow reserve, wall stress, and filling pressure and increases the activation of the sympathetic nervous system, which are associated with AF occurrence. At the same time, the proliferation and differentiation of fibroblasts into myofibroblasts cause disturbances in extracellular matrix. Studies suggested that the cardiac extracellular matrix remodeling was significantly changed in the hypertensive patients with 


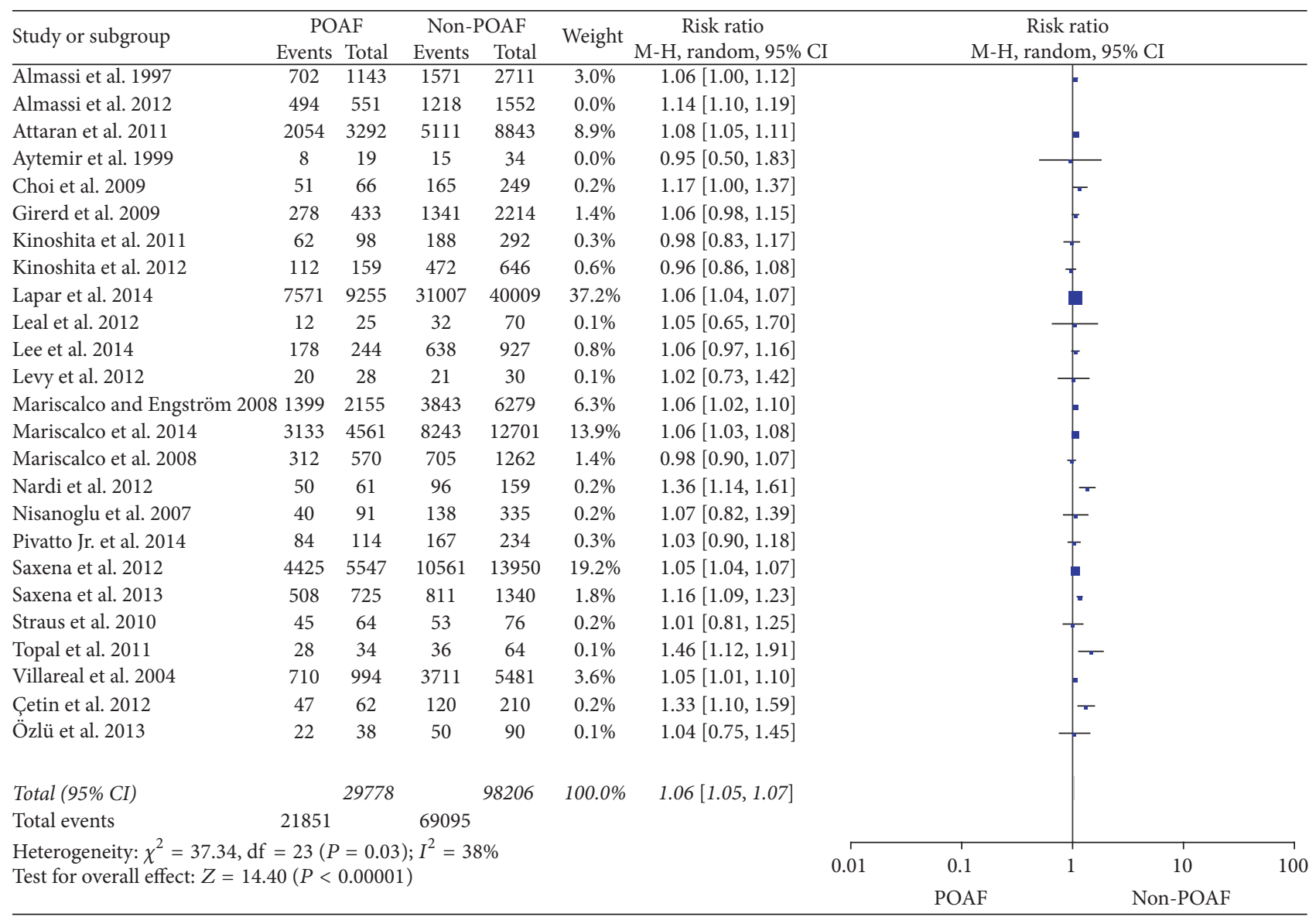

FIGURE 3: The effect of preoperative hypertension to POAF by sensitivity analysis.

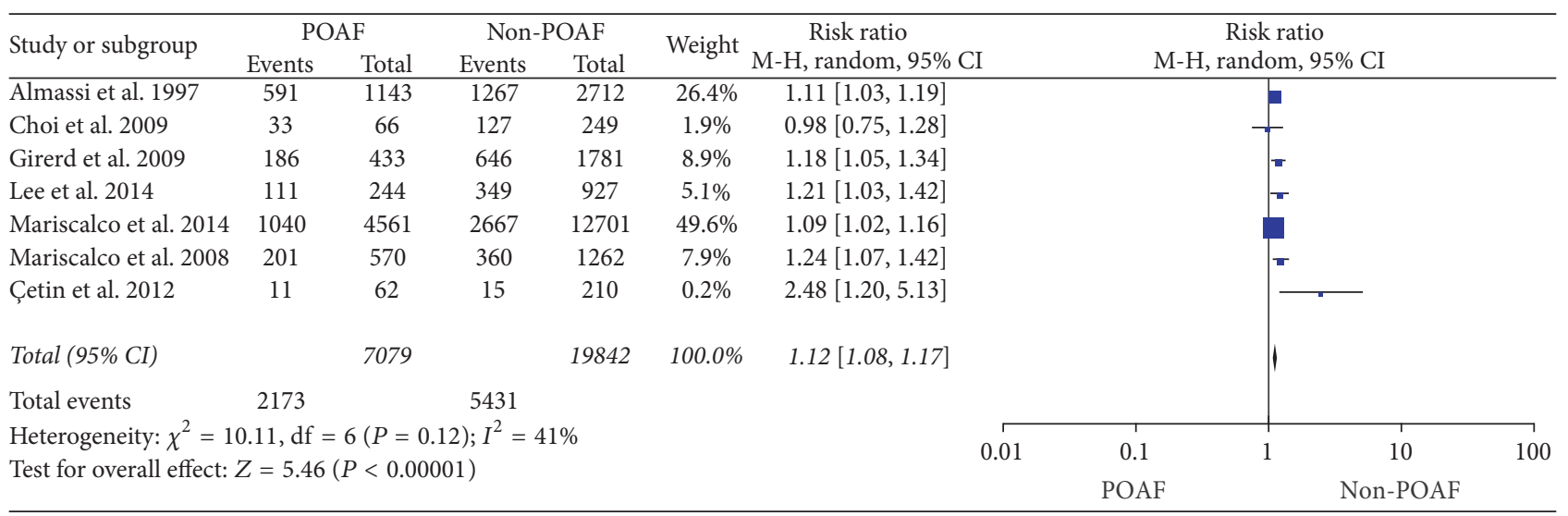

FIGURE 4: The effect of preoperative calcium antagonists regimen to POAF.

AF $[47,48]$. This may help explain why we found the numbers of preoperative hypertension patients in POAF group to be larger than Non-POAF group $(P<0.00001)$. Following consideration of the heterogeneity, we performed sensitivity analysis and subgroup analysis to talk about the potential reasons. We performed four sets of subgroup analysis and found the heterogeneity still exists in some groups (Table 2). We found that there is no significant difference between two groups in Asia patients with subgroup analysis, which is in contrast to other outcomes. Race factor may contribute to this result, while only four studies come from the Asia region and more studies are needed to confirm it. Then we omit the study of Almassi et al's [8] from 25 literatures; the $I^{2}$ drop to $38 \%$ and is accepted. Almassi compared the rate of POAF between on- and off-pump coronary artery bypass and found preoperative hypertension is a significant factor 


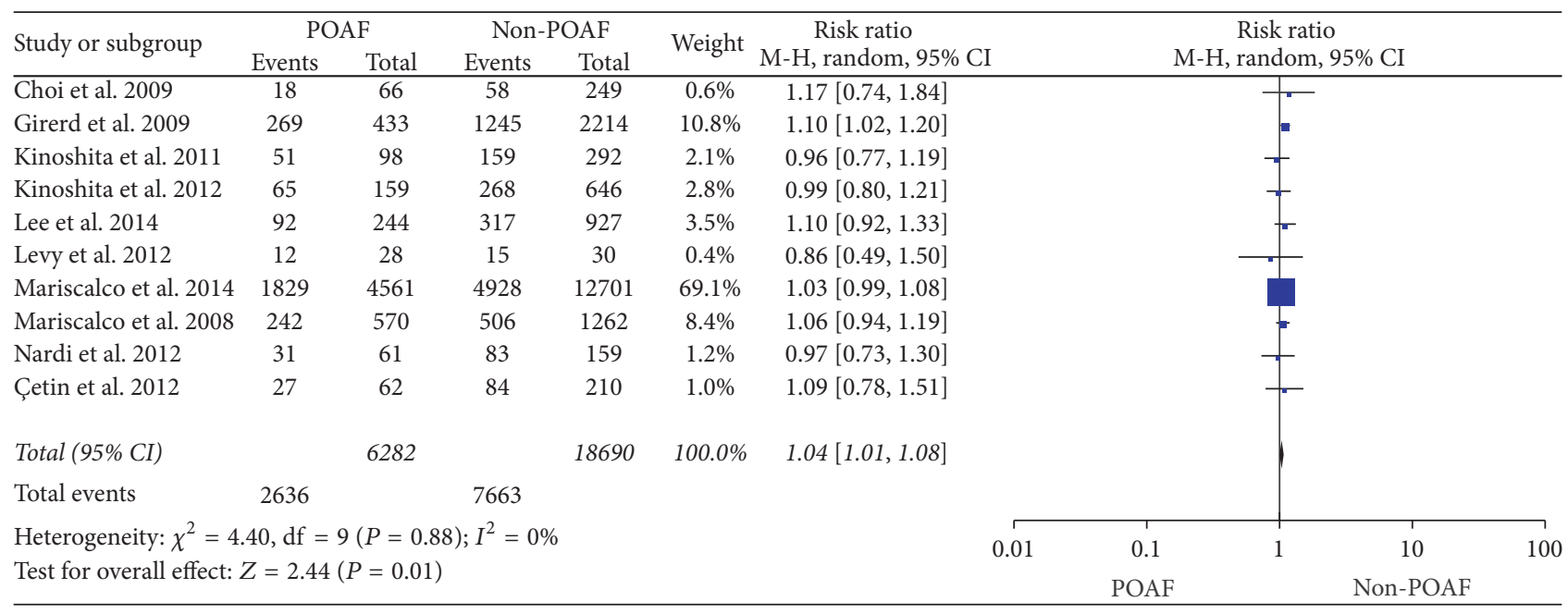

FIgURE 5: The effect of preoperative ACE inhibitors regimen to POAF.

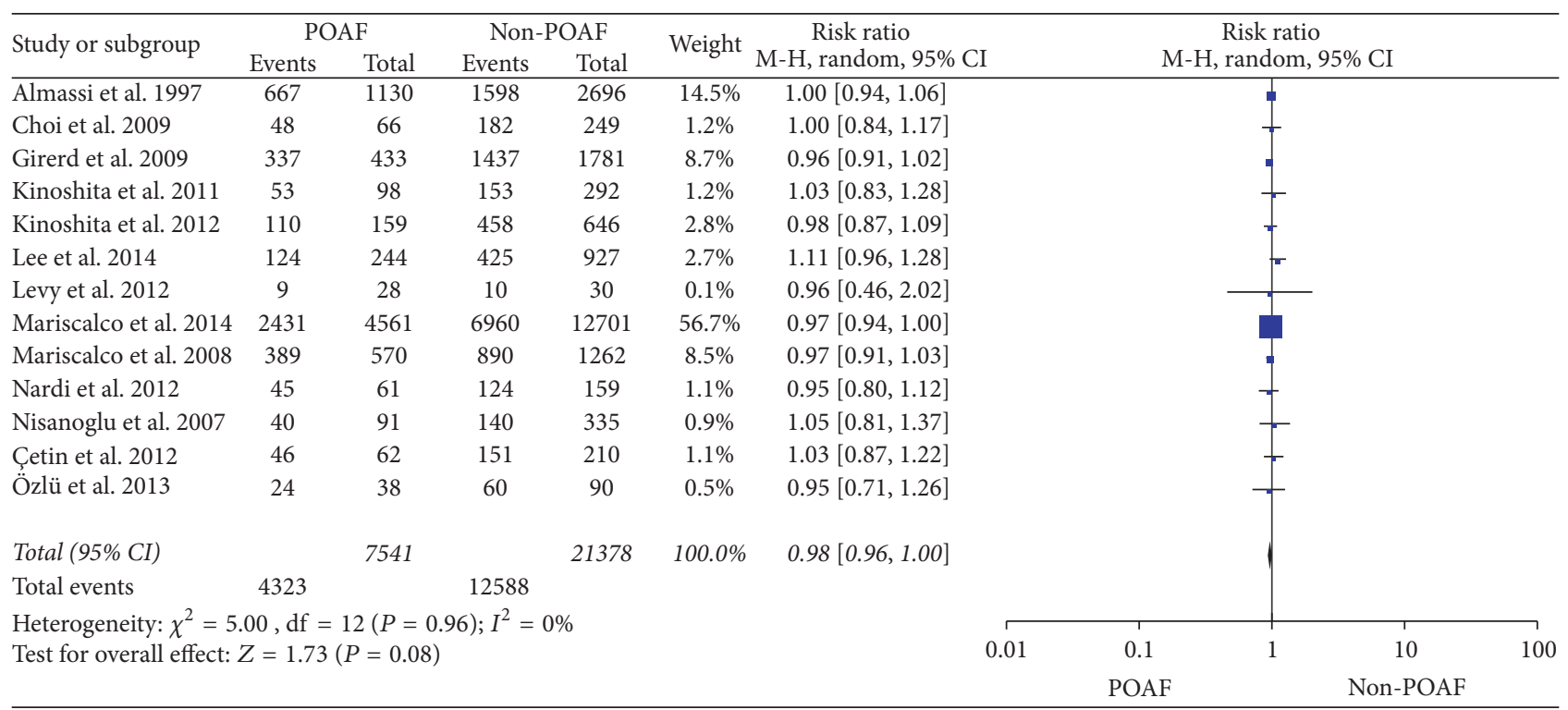

Figure 6: The effect of preoperative beta blocking agents regimen to POAF.

to POAF in on-pump coronary artery bypass group. Studies have confirmed a lower incidence of POAF in off-pump coronary artery bypass patients $[49,50]$. Other studies in our meta-analysis did not state the type of CABG similar to Almassi's study, which may be the cause of heterogeneity.

Antihypertensive drugs are prescribed mainly to reduce the morbidity and mortality caused by hypertension and its complications, while we observed that preoperative application of calcium antagonists and ACE inhibitors regimens is meaningful risk to POAF $(P<0.05)$. Read through those articles and attempt to find the confounding factors that influence the outcomes. Most of the studies did not perform logistic regression analysis except three studies [16, 27, 29]. Although $P$ values in three studies are all greater than 0.05 , the OR values in two studies $[16,29]$ are greater than 1 (Table 2). It may be telling us that calcium antagonists and
ACE inhibitors regimens have a positive effect on POAF, in spite of no significant difference existing. Several reasons contribute to the outcome: (1) preoperative application of calcium antagonists and ACE inhibitors regimens is significant risk factors to POAF and needs more studies to confirm it; (2) some confounding factors affect the results and need further analysis; (3) the myocardial excitability is higher in patients who apply calcium antagonists and ACE inhibitors preoperatively, for they usually stop these drugs postoperatively.

We recognize several limitations in our analysis. First, we performed an unavailable meta-analysis, and no access to individual patient data from individual studies was available. Second, this was a meta-analysis of observational studies. Subgroup analyses for some potential confounding of the association between preoperative hypertension and POAF 
were performed, and we did not find any strong subgroup effects. Third, none of the studies reported the association of different level hypertension in POAF in cardiac surgery patients, and therefore, we could not analyze this. Finally, this meta-analysis was based on studies published in the English language and unpublished literature could be missing, which may have generated bias.

\section{Conclusion}

Preoperative hypertension in patients undergoing cardiac operations seems to be associated with higher risk of POAF. Considering the limitations of this study, our finding should be reviewed with caution, and large-scale studies are needed to confirm our findings.

\section{Abbreviations}

RR: $\quad$ Risk ratios

CABG: Coronary artery bypass grafting

AVR: Aortic valve replacement

NOS: Newcastle-Ottawa Scale

POAF: Postoperative atrial fibrillation

AF: Atrial fibrillation.

\section{Competing Interests}

The authors declare that they have no competing interests.

\section{Authors' Contributions}

Ai-Guo Zhou and Xian-Xue Wang conceived the study, participated in the study design, collected the data, and drafted the manuscript. Xian-Xue Wang, Dao-Bo Pan, and An-ji Chen participated in the study design, collected the data, performed the statistical analysis, and contributed to drafting the manuscript. Xiong-fei Zhang and Hui-wei Deng helped to perform the statistical analysis and revised the manuscript critically to ensure all important intellectual content was present. All authors read and approved the final manuscript.

\section{References}

[1] M. Zakkar, R. Ascione, A. F. James, G. D. Angelini, and M. S. Suleiman, "Inflammation, oxidative stress and postoperative atrial fibrillation in cardiac surgery," Pharmacology and Therapeutics, vol. 154, pp. 13-20, 2015.

[2] A. Bessissow, J. Khan, P. J. Devereaux, J. Alvarez-Garcia, and P. Alonso-Coello, "Postoperative atrial fibrillation in non-cardiac and cardiac surgery: an overview," Journal of Thrombosis and Haemostasis, vol. 13, supplement 1, pp. S304-S312, 2015.

[3] D. C. Brooks and J. L. Schindler, "Perioperative stroke: risk assessment, prevention and treatment," Current Treatment Options in Cardiovascular Medicine, vol. 16, no. 2, article 282, 2014.

[4] M. F. El-Chami, P. Kilgo, V. Thourani et al., "New-onset atrial fibrillation predicts long-term mortality after coronary artery bypass graft," Journal of the American College of Cardiology, vol. 55, no. 13, pp. 1370-1376, 2010.

[5] F. Philip, M. Becker, J. Galla, E. Blackstone, and S. R. Kapadia, "Transient post-operative atrial fibrillation predicts short and long term adverse events following CABG," Cardiovascular Diagnosis and Therapy, vol. 4, no. 5, pp. 365-372, 2014.

[6] G. Mariscalco, F. Biancari, M. Zanobini et al., "Bedside tool for predicting the risk of postoperative atrial fibrillation after cardiac surgery: the POAF score," Journal of the American Heart Association, vol. 3, no. 2, Article ID e000752, 2014.

[7] G. Mariscalco, C. Klersy, M. Zanobini et al., "Atrial fibrillation after isolated coronary surgery affects late survival," Circulation, vol. 118, no. 16, pp. 1612-1618, 2008.

[8] G. H. Almassi, S. A. Pecsi, J. F. Collins, A. L. Shroyer, M. A. Zenati, and F. L. Grover, "Predictors and impact of postoperative atrial fibrillation on patients' outcomes: a report from the randomized on versus off bypass trial," Journal of Thoracic and Cardiovascular Surgery, vol. 143, no. 1, pp. 93-102, 2012.

[9] V. Nisanoglu, N. Erdil, M. Aldemir et al., "Atrial fibrillation after coronary artery bypass grafting in elderly patients: incidence and risk factor analysis," Thoracic and Cardiovascular Surgeon, vol. 55, no. 1, pp. 32-38, 2007.

[10] S. Straus, M. Kacila, E. Omerbasic et al., "Atrial fibrillation and coronary bypass surgery-what can be risk factors for its' appearance?" Bosnian Journal of Basic Medical Sciences, vol. 10, no. 1, pp. 78-82, 2010.

[11] S. B. Wells, D. O'Connell, J. Peterson et al., The NewcastleOttawa Scale (NOS) for assessing the quality of nonrandomized studies in meta-analyses, http://www.ohri.ca/programs/ clinical_epidemiology/oxford.asp.

[12] S.-H. Lee, D. R. Kang, J.-S. Uhm et al., "New-onset atrial fibrillation predicts long-term newly developed atrial fibrillation after coronary artery bypass graft," American Heart Journal, vol. 167, no. 4, pp. 593-600, 2014.

[13] G. Mariscalco and K. G. Engström, "Atrial fibrillation after cardiac surgery: risk factors and their temporal relationship in prophylactic drug strategy decision," International Journal of Cardiology, vol. 129, no. 3, pp. 354-362, 2008.

[14] F. Pivatto Jr., F. G. F. Teixeira, J. R. Santanna et al., "Advanced age and incidence of atrial fibrillation in the postoperative period of aortic valve replacement," Brazilian Journal of Cardiovascular Surgery, vol. 29, no. 1, pp. 45-50, 2014.

[15] S. Attaran, M. Shaw, L. Bond, M. D. Pullan, and B. M. Fabri, "Atrial fibrillation postcardiac surgery: a common but a morbid complication," Interactive Cardiovascular and Thoracic Surgery, vol. 12, no. 5, pp. 772-777, 2011.

[16] N. Girerd, P. Pibarot, D. Fournier et al., "Middle-aged men with increased waist circumference and elevated C-reactive protein level are at higher risk for postoperative atrial fibrillation following coronary artery bypass grafting surgery," European Heart Journal, vol. 30, no. 10, pp. 1270-1278, 2009.

[17] T. Kinoshita, T. Asai, T. Suzuki, A. Kambara, and K. Matsubayashi, "Preoperative hemoglobin Alc predicts atrial fibrillation after off-pump coronary bypass surgery," European Journal of Cardio-thoracic Surgery, vol. 41, no. 1, pp. 102-107, 2012.

[18] R. P. Villareal, R. Hariharan, B. C. Liu et al., "Postoperative atrial fibrillation and mortality after coronary artery bypass surgery," Journal of the American College of Cardiology, vol. 43, no. 5, pp. 742-748, 2004.

[19] A. E. Topal and M. N. Eren, "Predictors of atrial fibrillation occurrence after coronary artery bypass graft surgery," General 
Thoracic and Cardiovascular Surgery, vol. 59, no. 4, pp. 254-260, 2011.

[20] T. Kinoshita, T. Asai, T. Ishigaki, T. Suzuki, A. Kambara, and K. Matsubayashi, "Preoperative heart rate variability predicts atrial fibrillation after coronary bypass grafting," Annals of Thoracic Surgery, vol. 91, no. 4, pp. 1176-1182, 2011.

[21] A. Saxena, D. T. Dinh, J. A. Smith, G. C. Shardey, C. M. Reid, and A. E. Newcomb, "Usefulness of postoperative atrial fibrillation as an independent predictor for worse early and late outcomes after isolated coronary artery bypass grafting (multicenter australian study of 19,497 patients)," The American Journal of Cardiology, vol. 109, no. 2, pp. 219-225, 2012.

[22] D. J. Lapar, A. M. Speir, I. K. Crosby et al., "Postoperative atrial fibrillation significantly increases mortality, hospital readmission, and hospital costs," Annals of Thoracic Surgery, vol. 98, no. 2, pp. 527-533, 2014.

[23] G. H. Almassi, T. Schowalter, A. C. Nicolosi et al., "Atrial fibrillation after cardiac surgery: a major morbid event?" Annals of Surgery, vol. 226, no. 4, pp. 501-513, 1997.

[24] A. Saxena, W. Y. Shi, S. Bappayya et al., "Postoperative atrial fibrillation after isolated aortic valve replacement: a cause for concern?" Annals of Thoracic Surgery, vol. 95, no. 1, pp. 133-140, 2013.

[25] J. C. Leal, O. Petrucci, M. F. Godoy, and D. M. Braile, "Perioperative serum troponin i levels are associated with higher risk for atrial fibrillation in patients undergoing coronary artery bypass graft surgery," Interactive Cardiovascular and Thoracic Surgery, vol. 14, no. 1, pp. 22-25, 2012.

[26] Y. S. Choi, J. K. Shim, S. W. Hong, D. H. Kim, J. C. Kim, and Y. L. Kwak, "Risk factors of atrial fibrillation following offpump coronary artery bypass graft surgery: predictive value of C-reactive protein and transfusion requirement," European Journal of Cardio-Thoracic Surgery, vol. 36, no. 5, pp. 838-843, 2009.

[27] F. Nardi, M. Diena, P. P. Caimmi et al., "Relationship between left atrial volume and atrial fibrillation following coronary artery bypass grafting," Journal of Cardiac Surgery, vol. 27, no. 1, pp. 128-135, 2012.

[28] M. F. Özlü, K. Erdem, G. Kiriş et al., "Predictive value of total atrial conduction time measured with tissue Doppler imaging for postoperative atrial fibrillation after coronary artery bypass surgery," Journal of Interventional Cardiac Electrophysiology, vol. 37, no. 1, pp. 27-33, 2013.

[29] M. Çetin, S. A. L. Kocaman, T. Erdoğan et al., "Fragmented QRS may predict postoperative atrial fibrillation in patients undergoing isolated coronary artery bypass graft surgery," Anadolu Kardiyoloji Dergisi, vol. 12, no. 7, pp. 576-583, 2012.

[30] F. Levy, N. Debry, A. L. Labescat et al., "Echocardiographic prediction of postoperative atrial fibrillation after aortic valve replacement for aortic stenosis: a two-dimensional speckle tracking left ventricular longitudinal strain multicentre pilot study," Archives of Cardiovascular Diseases, vol. 105, no. 10, pp. 499-506, 2012.

[31] K. Aytemir, S. Aksoyek, N. Ozer, S. Aslamaci, and A. Oto, "Atrial fibrillation after coronary artery bypass surgery: P wave signal averaged ECG, clinical and angiographic variables in risk assessment," International Journal of Cardiology, vol. 69, no. 1, pp. 49-56, 1999.

[32] A. E. Contreras, A. F. Guadagnoli, E. J. Brenna et al., "Atrial fibrillation in postoperative cardiac surgery: prevalence and hospitalized period," Medicina, vol. 70, no. 4, pp. 339-342, 2010.
[33] Z. K. Wu, T. Livainen, E. Pehkonen et al., "Fibrillation in patients subjected to coronary artery bypass grafting," The Journal of Thoracic and Cardiovascular Surgery, vol. 126, no. 5, pp. 14771482, 2003.

[34] P. Singhal and N. Kejriwal, "Right atrial pacing for prevention of postoperative atrial fibrillation following coronary artery bypass grafting: a prospective observational trial," Heart Lung and Circulation, vol. 19, no. 7, pp. 395-399, 2010.

[35] A. Kollar, S. D. Lick, K. N. Vasquez, and V. R. Conti, "Relationship of atrial fibrillation and stroke after coronary artery bypass graft surgery: when is anticoagulation indicated?" Annals of Thoracic Surgery, vol. 82, no. 2, pp. 515-523, 2006.

[36] D. K. Murdock, L. R. Rengel, A. Schlund et al., "Stroke and atrial fibrillation following cardiac surgery," Wisconsin Medical Journal, vol. 102, no. 4, pp. 26-30, 2003.

[37] W. E. Cohn, C. A. Sirois, and R. G. Johnson, "Atrial fibrillation after minimally invasive coronary artery bypass grafting: a retrospective, matched study," Journal of Thoracic and Cardiovascular Surgery, vol. 117, no. 2, pp. 298-301, 1999.

[38] P. R. Kowey, D. Stebbins, L. Igidbashian et al., "Clinical outcome of patients who develop PAF after CABG surgery," Pacing and Clinical Electrophysiology, vol. 24, no. 2, pp. 191-193, 2001.

[39] M. H. Kim, G. M. Deeb, F. Morady et al., "Effect of postoperative atrial fibrillation on length of stay after cardiac surgery (the postoperative atrial fibrillation in cardiac surgery study $\left[\mathrm{PACS}^{2}\right]$ )," The American Journal of Cardiology, vol. 87, no. 7, pp. 881-885, 2001.

[40] M. K. Lahiri, K. Fang, L. Lamerato, A. M. Khan, and C. D. Schuger, "Effect of race on the frequency of postoperative atrial fibrillation following coronary artery bypass grafting," The American Journal of Cardiology, vol. 107, no. 3, pp. 383-386, 2011.

[41] M. Hravnak, L. A. Hoffman, M. I. Saul, T. G. Zullo, G. R. Whitman, and B. P. Griffith, "Predictors and impact of atrial fibrillation after isolated coronary artery bypass grafting," Critical Care Medicine, vol. 30, no. 2, pp. 330-337, 2002.

[42] W. E. Cohn, I. D. Gregoric, B. Radovancevic, R. K. Wolf, and O. H. Frazier, "Atrial fibrillation after cardiac transplantation: experience in 498 consecutive cases," Annals of Thoracic Surgery, vol. 85, no. 1, pp. 56-58, 2008.

[43] P. Wierup, H. Lidén, B. Johansson, M. Nilsson, N. Edvardsson, and E. Berglin, "Health care consumption due to atrial fibrillation is markedly reduced by maze III surgery," Annals of Thoracic Surgery, vol. 83, no. 5, pp. 1713-1716, 2007.

[44] M. Fatemi, M. Leledy, G. Le Gal, E. Bezon, P. Mondine, and J.-J. Blanc, "Atrial flutter after non-congenital cardiac surgery: incidence, predictors and outcome," International Journal of Cardiology, vol. 153, no. 2, pp. 196-201, 2011.

[45] L. Frost, H. Mølgaard, E. H. Christiansen, C.-J. Jacobsen, H. Pilegaard, and P. E. B. Thomsen, "Atrial ectopic activity and atrial fibrillation/flutter after coronary artery bypass surgery. A case-base study controlling for confounding from age, $\beta$ blocker treatment, and time distance from operation," International Journal of Cardiology, vol. 50, no. 2, pp. 153-162, 1995.

[46] J. G. Wang, J. T. Xi, Z. M. Zhao et al., "Analysis of left atrial lesions in elderly patients with essential hypertension and atrial fibrillation," Chinese Journal of Cardiovascular Research, vol. 13, no. 12, pp. 1109-1111, 2015.

[47] M. Tadic, B. Ivanovic, and C. Cuspidi, "What do we actually know about the relationship between arterial hypertension and atrial fibrillation?” Blood Pressure, vol. 23, no. 2, pp. 81-88, 2014.

[48] A. S. Kalogeropoulos, S. Tsiodras, A. G. Rigopoulos et al., "Novel association patterns of cardiac remodeling markers 
in patients with essential hypertension and atrial fibrillation," BMC Cardiovascular Disorders, vol. 11, article 77, 2011.

[49] R. Ascione, M. Caputo, G. Calori, C. T. Lloyd, M. J. Underwood, and G. D. Angelini, "Predictors of atrial fibrillation after conventional and beating heart coronary surgery: a prospective, randomized study," Circulation, vol. 102, no. 13, pp. 1530-1535, 2000.

[50] J. T. Reston, S. J. Tregear, and C. M. Turkelson, "Meta-analysis of short-term and mid-term outcomes following off-pump coronary artery bypass grafting," Annals of Thoracic Surgery, vol. 76, no. 5, pp. 1510-1515, 2003. 


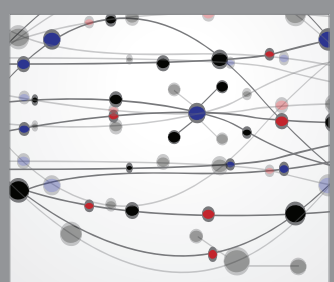

The Scientific World Journal
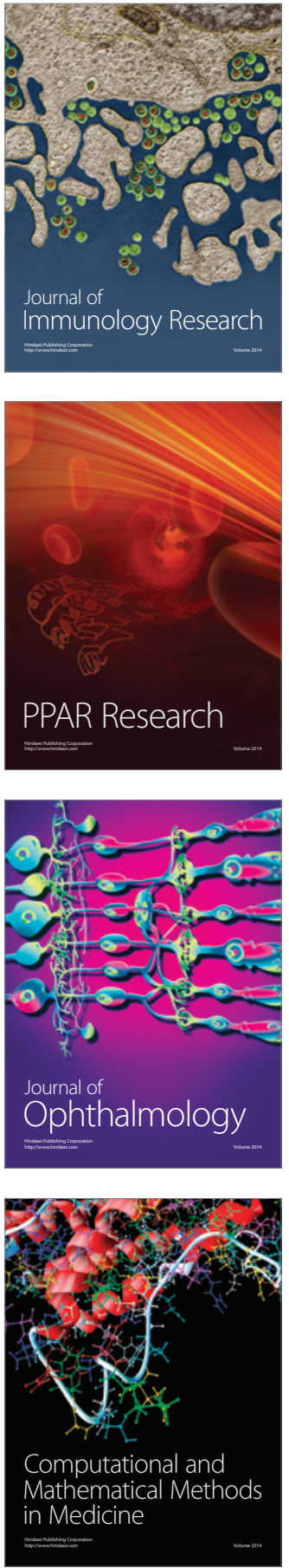

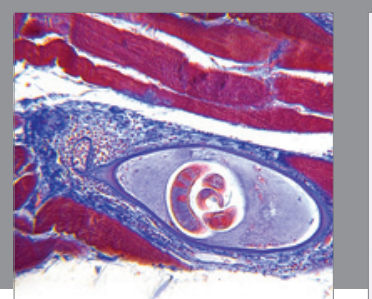

Gastroenterology Research and Practice
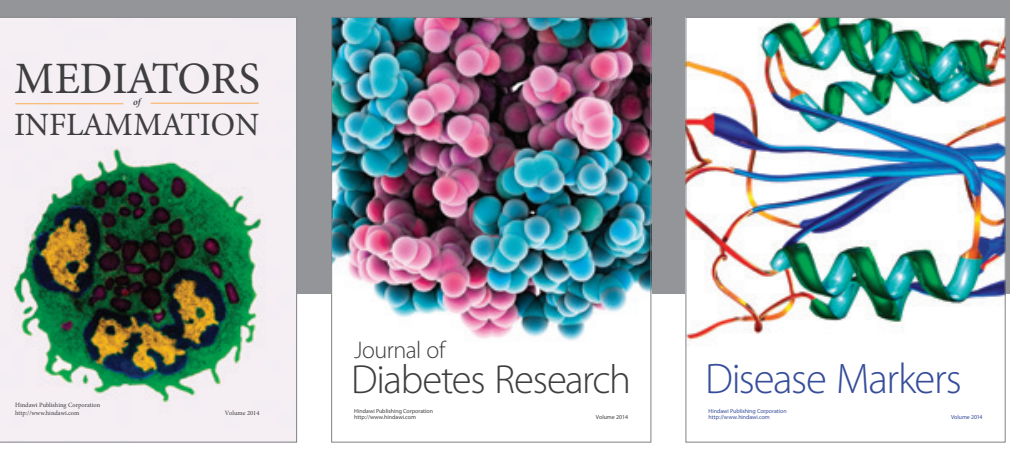

Disease Markers

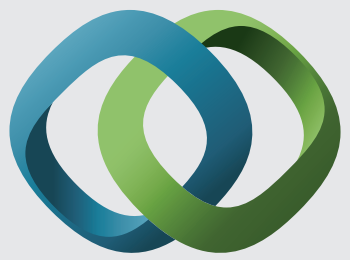

\section{Hindawi}

Submit your manuscripts at

https://www.hindawi.com
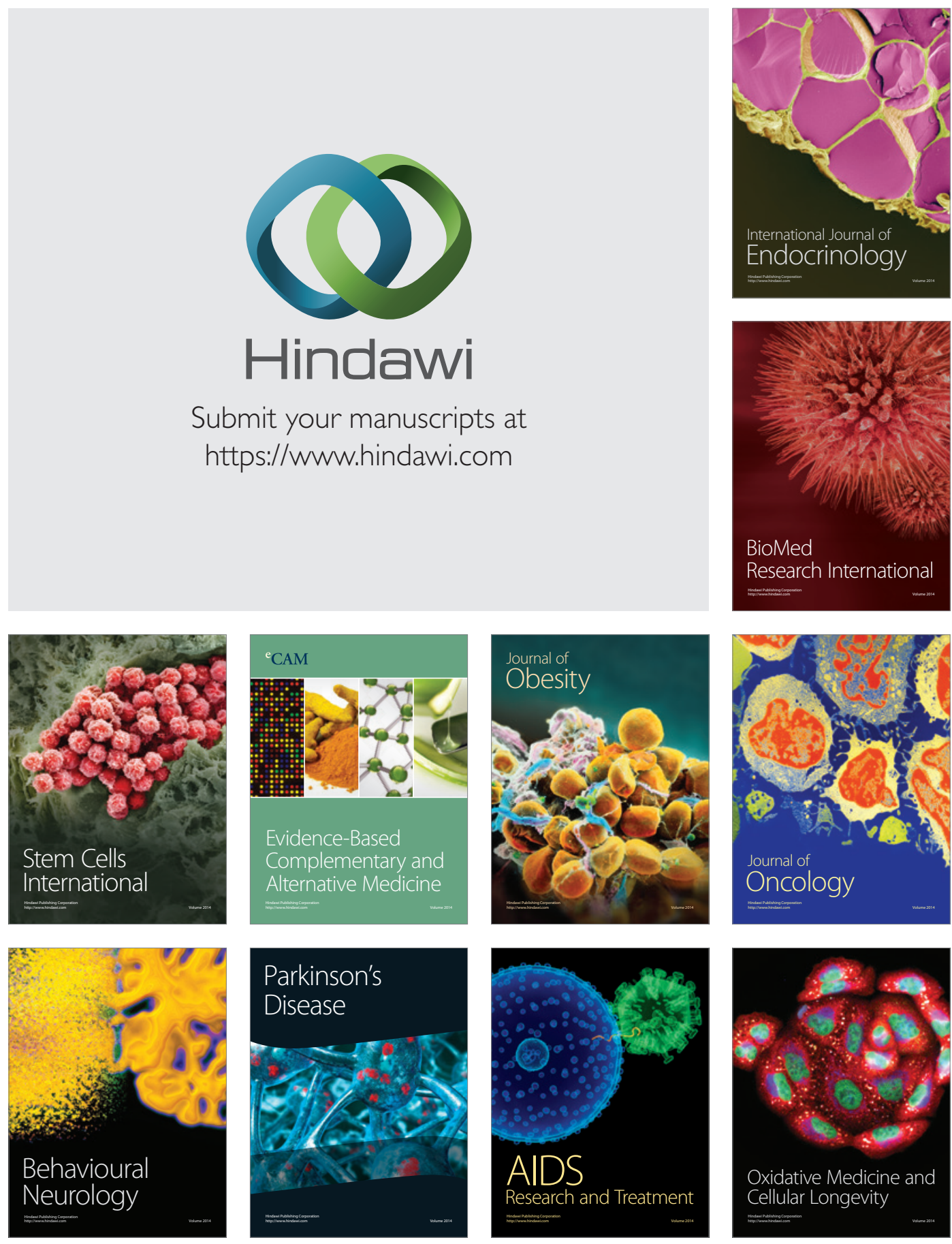